\title{
Periodontitis in Patients with Diabetes- A Complication that Impacts on Metabolic Control
}

\author{
Corneliu Sima, DMD, DSc ${ }^{1}$ and Michael Glogauer, DDS, PhD² \\ 1. Post-doctoral Fellow and Senior Resident in Periodontology, Faculty of Dentistry; \\ 2. Associate Professor, Faculty of Dentistry and Faculty of Medicine, University of Toronto, Ontario, Canada
}

\begin{abstract}
Diabetes and periodontal diseases (PDS) exhibit a bidirectional relationship centered on an enhanced inflammatory response that manifests both locally and systemically. Diabetes is an established risk factor for PD, whereas the treatment of the latter has been shown to improve glycemic control in diabetic patients. Although compelling evidence from in vitro and animal studies supports a plausible biological explanation for the relationship between the two conditions centered on systemic low-grade inflammation, the limited number of comparable large randomized clinical trials is reflected in the limited specific guidelines offered by the international organizations for diabetes and periodontitis regarding the management of the two diseases in an individual. Further understanding of the biological phenomena underlying PDs and diabetes is critical for individual therapeutic approaches to patients with both conditions by endocrinologists and periodontists.
\end{abstract}

\section{Keywords}

Diabetes, periodontal diseases, inflammation, glycemic control

Disclosure: The authors have no conflicts of interest to declare.

Received: June 5, 2012 Accepted: June 27, 2012 Citation: US Endocrinology, 2012;8(1):35-9 DOl: 10.17925/USE.2012.08.01.35

Correspondence: Michael Glogauer, DDS, PhD, Associate Professor, Faculty of Dentistry and Faculty of Medicine, University of Toronto, Room 221, Fitzgerald Building,

150 College Street, Toronto, Ontario, M5S 3E2, Canada. E: michael.glogauer@utoronto.ca

Diabetes is a multifactorial, life-threatening chronic disease characterized by a dysregulation of the endocrine and metabolic pathways involved in the control of blood glucose levels resulting in hyperglycemia. Uncontrolled diabetes gradually impacts on the nervous and circulatory systems, resulting in irreversible long-term complications. In 2010, approximately $8.3 \%$ of the US population-or 25.8 million people-had diabetes either diagnosed (18.8 million) or undiagnosed (7.0 million) and a further 79 million people were estimated to have pre-diabetes according to the Centers for Disease Control and Prevention. ${ }^{1}$ Chronic hyperglycemia is a hallmark of diabetes regardless of the pathophysiological mechanism of the disease and is regarded as a central player in the development of acute complications-such as hypoglycemic coma, ketoacidotic coma, hyperosmolar non-ketonic coma, myocardial infarction (MI), and stroke-and chronic complications-such as diabetic nephropathy, retinopathy, neuropathy, cardiovascular diseases, peripheral vascular diseases, and periodontal diseases (PDS).

PDS are chronic, microbially induced inflammatory disorders of the tooth-supporting tissues (periodontium) characterized by the progressive destruction of those tissues and ultimately resulting in tooth loss. PDs are the most common inflammatory and bone lytic diseases of humans. Up to $75 \%$ of North American adults experience the morbidity and decreased oral function associated with alveolar bone destruction and subsequent edentulism during their lifetime. Oral bone
Ioss takes on additional importance because of recent evidence linking PDs with systemic health conditions including diabetes, cardiovascular disease, and cancer as well as with giving birth to premature children.

Periodontitis, like several other bone diseases (e.g., osteoporosis), is not usually diagnosed until bone loss is well established and damage to skeletal structures has already occurred. Chronic inflammation of gingival tissues called gingivitis represents the initial reversible stage of PD. Although, in some individuals, gingivitis never progresses to PD, ${ }^{2}$ data suggest that gingivitis always precedes PD and, more importantly, that it represents a clinically relevant risk factor for periodontal attachment loss. ${ }^{3}$ PD represents the advancement of tissue destruction in the underlying periodontal structures-including the periodontal ligament (PDL), cementum covering the root surfaces, and alveolar bone-compromising tooth stability in the socket (see Figure 1).

In general, three parameters are used to evaluate periodontal status: bleeding on probing (BOP) as indicator of gingivitis, and clinical attachment level (CAL) and alveolar bone loss ( $A B L$ ) as indices for monitoring PD progression. The quality and quantity of gingival crevicular fluid (GCF), a pseudo-inflammatory exudate found in the gingival crevice, may also be assessed for diagnostic and disease monitoring purposes. Progression of gingivitis to PD is characterized by dysregulated host-biofilm interactions and a failure to resolve local inflammation induced by periodontopathogenic bacteria. 


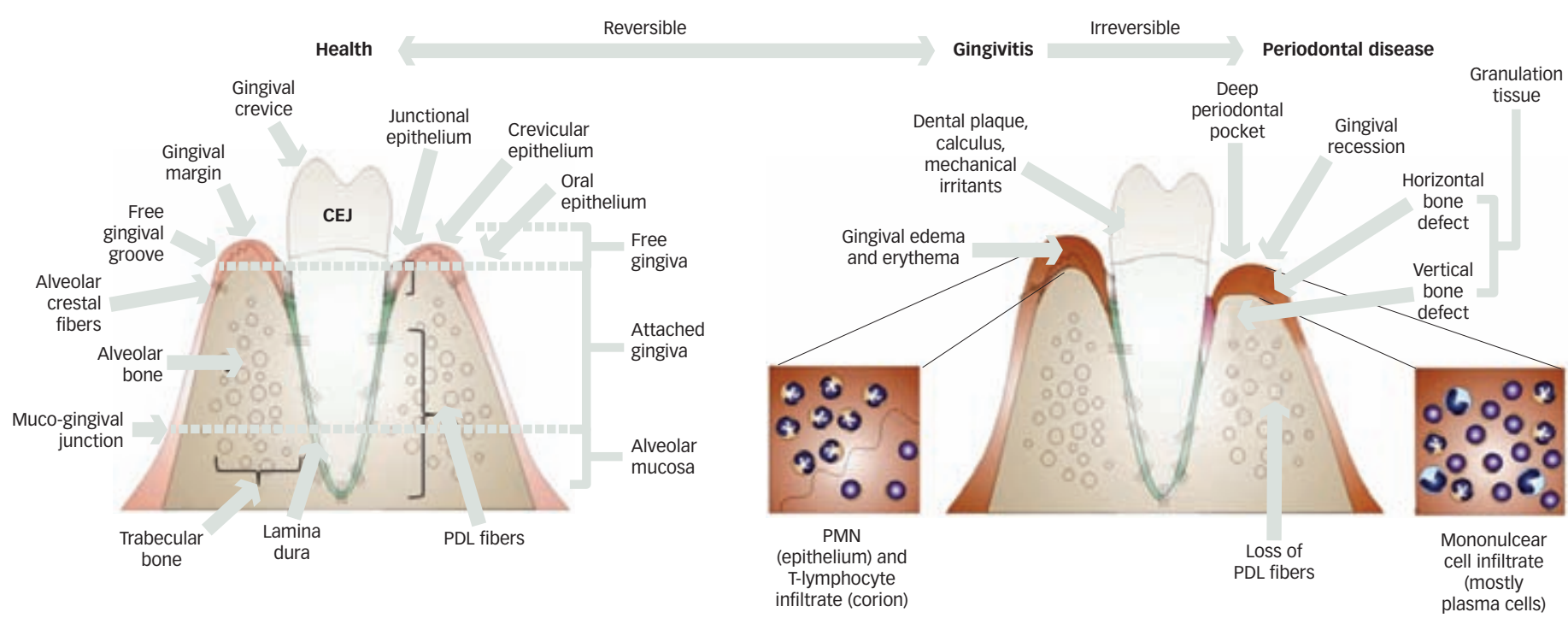

In health, periodontal tissues ensure the adequate protection of tooth root surfaces, anchorage and support for the tooth, and absorption and transfer of masticatory forces to the underlying bone. The periodontium is formed of gingival tissues, alveolar bone, PDL (fibers, cells, and extracellular matrix), and cementum covering the root surfaces. The crevice formed between the tooth and gingiva contains an inflammatory exudate that helps protect the junctional epithelium from dental plaque by-products and other irritants. Persistence of dental plaque for up to 21 days and its compositional changes within this interval induce gingivitis, which is characterized by hyperemic tumefaction of free gingiva, an inflammatory PMN infiltrate, and relatively high numbers of

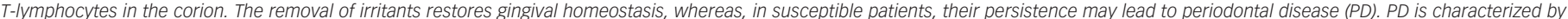

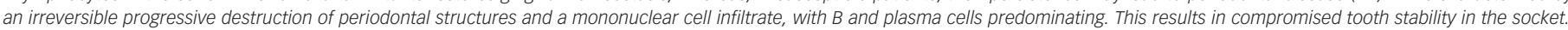
$C E J=$ cementoenamel junction; $P D L=$ periodontal ligament; $P M N=$ polymorphonuclear neutrophil.

This short article overviews the role of diabetes as a risk factor for PD, the impact of PD on diabetic complications and incident diabetes, the effect of periodontal therapy on glycemic control in patients with diabetes, and potential mechanisms linking diabetes and PD.

\section{Diabetes as a Risk Factor for Periodontal Disease}

The benefits of glycemic control in patients with diabetes in order to prevent complications have been extensively reported in the literature. The Diabetes control and complications trial (DCCT) ${ }^{4}$ and the UK Prospective Diabetes Study (UKDPS), ${ }^{5}$ two landmark prospective studies on type 1 and type 2 diabetes, have demonstrated that intensive therapy aimed at blood glucose control reduces the risk of microvascular complications and slows the progression of retinopathy, nephropathy, and neuropathy in diabetic patients. Furthermore, metformin alone significantly reduced the risk of macrovascular disease (myocardial infarction, stroke) and tight blood pressure control significantly reduced the risk of both micro- and macrovascular complications..$^{4-6}$ In addition to these complications, PD had been proposed as a sixth diabetic complication. ${ }^{7}$ An association between diabetes and PD has been reported in the literature since the 1960s. ${ }^{8,9}$ The impact of diabetes on periodontal health has been addressed in numerous cross-sectional and Iongitudinal studies, and diabetes is currently established as a risk factor for PD. Although there is significant heterogeneity between the studies in design and in definition of PD, increasing evidence suggests that poorly controlled diabetes correlates with higher prevalence, severity, and progression rate of PD, compared with controlled diabetes or health. ${ }^{10-14}$

Gingivitis is more prevalent in diabetic patients than in healthy individuals regardless of dental plaque index, suggesting an impact of diabetes on local inflammatory response to the bacterial biofilm. ${ }^{15-18}$ In support of this observation, levels of pro-inflammatory cytokines measured in gingival tissues or GCF-in particular interleukin-1 beta (IL-1 $\beta$ )-are increased in patients with poorly controlled diabetes in the absence of PD, compared with non-diabetics and with patients whose diabetes is well controlled. ${ }^{19}$ Salvi et al. have reported increasing IL-1 $\beta$ levels in the GCF of patients with or without type 1 diabetes during 21-day experimental gingivitis, with a significant increase in diabetic patients on Day 7 and one week later in healthy individuals. ${ }^{20}$ These observations suggest that diabetes favors a gingival pro-inflammatory state prior to onset of PD.

Progression of gingivitis to $\mathrm{PD}$, generally measured by clinical CAL and $A B L$ parameters, also correlates with diabetes and control of the blood glucose (BG). However, the relationship between metabolic control and $\mathrm{PD}$ is difficult to define conclusively, since some poorly controlled diabetics do not develop PD and some well controlled diabetics do develop PD. The prevalence of PD is three times higher in poorly controlled diabetics compared with well controlled diabetics and non-diabetics, according to a large population-based cross-sectional study in the US. ${ }^{21}$ Several studies have shown that there is a correlation between glycated hemoglobin $\left(\mathrm{HbA}_{1 \mathrm{c}}\right)$ levels and prevalence of $\mathrm{PD}$ in diabetic patients, and that CAL is more severe, with more probing depths greater than $3.5 \mathrm{~mm}$, in patients with uncontrolled diabetes. ${ }^{21-25}$ On the contrary, some studies have found little or no correlation between glycemic control and periodontal health-but most of them included younger populations who have a generally lower prevalence of PD. ${ }^{26-28}$ This discrepancy in findings between studies may be due to other metabolic variables not having been taken into account. In fact, one study found a higher correlation between dyslipidemia and PD than between BG control and PD in diabetic patients. ${ }^{29}$ Others have 
reported positive correlations between obesity, dyslipidemia, and prevalence and severity of PD in different age groups. ${ }^{30-32}$ Interestingly, in some diabetic patients, subgingival microflora is predominated by Gram-negative bacteria, particularly rods and fusiforms, partially explaining the higher risk of CAL. ${ }^{28,33}$

\section{Impact of Periodontal Disease on Diabetic Complications and Incident Diabetes}

Two major longitudinal studies with a median follow-up of six and 11 years have linked PD with an increased risk of cardiorenal diabetic complications in patients with type 1 and type 2 diabetes. The first study found a higher incidence of proteinuria and cardiovascular complications_-including angina, intermittent claudication, transient ischemic attack, MI, and stroke-in 39 paired Swedish type 1 diabetes patients with severe PD compared with patients with no or mild PD. ${ }^{34}$ The second study looked at 628 Pima Indians with type 2 diabetes and demonstrated a significantly increased adjusted relative risk (3.2, $95 \%$ confidence interval [Cl] 1.1-9.3) of cardiorenal mortality in those with severe PD compared with a group who had no, mild, or moderate PD. ${ }^{35}$ Furthermore, PD and edentulism were found to predict incident microalbuminuria and end-stage renal disease in a sample of 529 patients with type 2 diabetes drawn from the same population..$^{36}$ These observations support the earlier one that severe PD in diabetic patients at baseline increases the risk of poor glycemic control at follow-up.

The only two longitudinal studies that investigated the risk of patients with PD developing type 2 diabetes were the first National health and nutrition examination survey (NHANES I) and its follow-up NHEFS (NHANES I epidemiologic follow up study) and a Japanese study, which included 9,296 and 5,848 individuals without diabetes, respectively. ${ }^{37,38}$ While the first study found an adjusted odds ratio of between 1.5 and 2.08 for incident diabetes in patients with high periodontal index scores or tooth loss at baseline, the second study found no association between PD and incident diabetes despite statistically significant positive associations in the unadjusted analyses. However, in both studies, the definition of PD as measure of exposure has been imprecise and thus the interpretation of their results should be made with caution.

\section{Periodontal Therapy and Glycemic Control}

Growing evidence suggests that treatment of PD, particularly mechanical root scaling/planing, improves metabolic control in patients with diabetes by significantly reducing $\mathrm{HbA}_{1 \mathrm{c}}$ levels, ${ }^{39,40}$ reducing circulating inflammatory mediators (C-reactive protein [CRP], tumor necrosis factor [TNF], IL-6, and fibrinogen) and increasing levels of adiponectin. ${ }^{41-44}$ Two recent systematic reviews ${ }^{45,46}$ overviewed data from

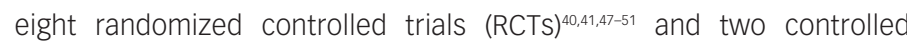
clinical trials (CCTs) ${ }^{52,53}$ of at least three months' duration that assessed the effects of mechanical periodontal therapy with or without adjunctive antimicrobials on glycemic control in diabetic patients (439 participants in total). The two systematic reviews concluded that the effect of periodontal therapy reduced $\mathrm{HbA}_{1 \mathrm{c}}$ levels by a significant $0.40 \%$ (95\% $\mathrm{Cl}-0.77$ to -0.04 and -0.78 to -0.01 , respectively). The two systematic reviews only had two studies ${ }^{47,48}$ in common, as their inclusion criteria differed slightly; their inclusion criteria were more strict than a those of a previous meta-analysis that had found a $0.46 \%$ decrease in $\mathrm{HbA}_{1 \mathrm{C}}$ levels following periodontal therapy. ${ }^{54}$ This reduction in $\mathrm{HbA}_{1 \mathrm{c}}$ levels may
Figure 2: Immunologic and Microvascular Gingival Changes in Diabetes

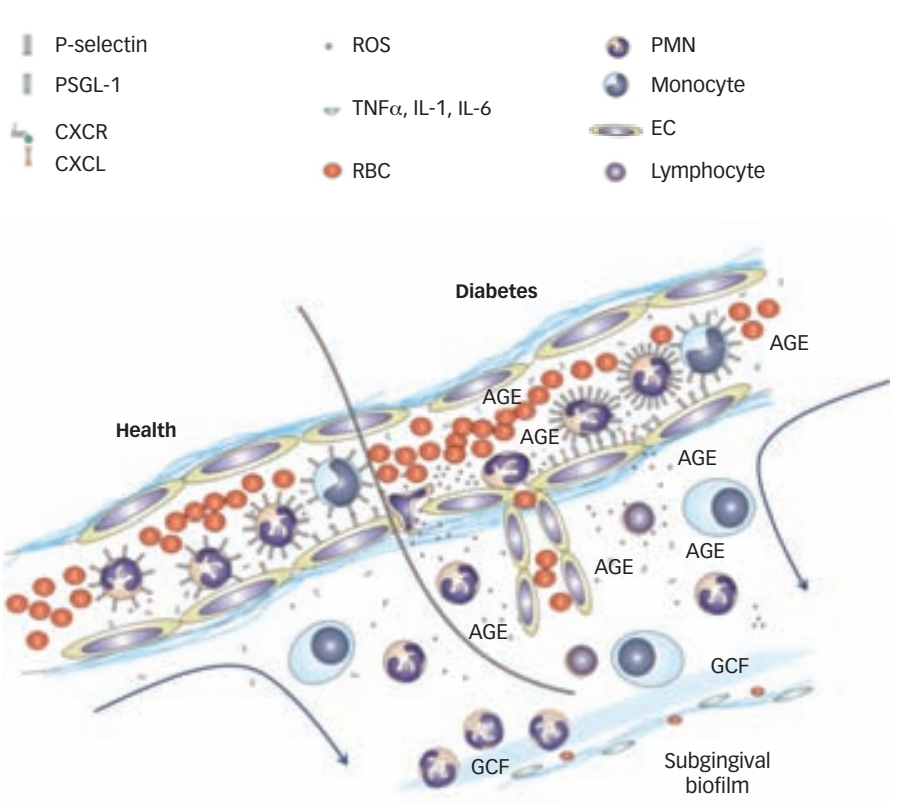

Oxidative stress and dysfunctional gingival leukocyte extravasation in diabetes correlate with increased severity and progression of periodontal disease most probably due to inefficient control of subgingival biofilm composition and tissue damage by leukocyte-derived factors such as ECM-degrading enzymes and ROS.

$A G E=$ advanced glycation endproducts; $G C F=$ gingival crevicular fluid; $C X C L=C X C$ chemokine ligand; $C X C R=C X C$ chemokine receptor; $E C=$ endothelial cell; $E C M=$ extracellular matrix; $I L=$ interleukin; PMN = polymorphonuclear neutrophil; PSGL-1 = P-selectin glycoprotein ligand-1; $R B C=$ red blood cell; $R O S=$ reactive oxygen species; $T N F \alpha=$ tumor necrosis factor alpha.

be significant, considering that the UKDPS study demonstrated a $35 \%$ reduction in the risk of cardiovascular complications with each percent reduction in $\mathrm{HbA}_{1 \mathrm{c}}$ levels in diabetic patients, ${ }^{55}$ and that a $0.2 \%$ $\mathrm{HbA}_{1 \mathrm{c}}$ reduction is associated with a $10 \%$ reduction in mortality in the general population. ${ }^{56}$ However, larger RCTs are needed to better understand the impact of PD treatment on glycemic control. Furthermore, the role of adjunctive systemic antibiotics has not yet been fully appreciated.

\section{Potential Mechanisms Linking Periodontal Disease and Diabetes}

Several mechanisms by which diabetes influences periodontal tissues have been proposed, including immunological dysfunctions, microvascular changes, and changes in extracellular matrix. ${ }^{57.58}$ Impairment of polymorphonuclear neutrophil adherence, chemotaxis and phagocytosis, ${ }^{59,60}$ and monocyte/macrophage hyper-responsiveness ${ }^{61,62}$ in diabetic patients may explain the higher prevalence and severity of PD in these individuals (see Figure 2). These alterations may result in ectopic inflammatory responses and tissue degradation. Monocyte hyperactivity may be reversed in patients with diabetes by scaling and root planing resulting in reduced monocyte-derived TNF $\alpha$, high-sensitivity CRP, and soluble E-selectin (sE-selectin). ${ }^{63}$ Increased leukocyte adhesion molecule expression and gingival microvascular permeability in diabetes without PD suggests an immune-vascular priming that predisposes to PD. ${ }^{64,65}$ Furthermore, inflammatory-mediated uncoupling of bone formation/resorptionis associated with hyperglycemia in the context of reduced osteoblast 
proliferation, differentiation, and collagen production could be reversed with insulin treatment. ${ }^{66-69}$

One plausible explanation for the link between PD and glycemic control is a low-grade inflammation measured as elevation in systemic pro-inflammatory markers. Mounting evidence suggests that periodontitis in healthy individuals raises the levels of pro-inflammatory and pro-thrombotic mediators in serum and that periodontal therapy is associated with a long-term reduction in pro-inflammatory markers (CRP, TNF $\alpha$, and plasminogen activator inhibitor-1) and an improvement of endothelial function (decreased levels of SE-selectin). ${ }^{63,70}$ A dose-response relationship between severity of PD and plasma levels of TNF $\alpha-a$ cytokine known to promote insulin resistance-was found in adults with type 2 diabetes. $^{71}$ The observation of high levels of albumin advanced glycation endproducts (AGE) in gingival tissues of diabetic mice has led to the hypothesis that AGE-mediated activation of inflammatory pathways in periodontium may explain in part the role of chronic hyperglycemia in PD. ${ }^{72}$ In support of this finding, a cross-sectional study including 69 patients with a mean age of 58 years diagnosed with type 2 diabetes and PD has found a significant association between serum AGE and severity of PD. ${ }^{73}$ In addition, advanced glycation of fibronectin and type I collagen significantly impaired human periodontal ligament fibroblasts by reducing their migratory and attaching properties. $^{74}$

PD may impact on glycemic control through transient bacteremia, which could contribute to the initiation and progression of atheroma plaques in arterial walls. This mechanism may involve direct infectious pathogenicity and systemic low-level inflammation that has been correlated with atherosclerosis and cardiovascular diseases. ${ }^{75-81}$ In support of this hypothesis, periodontal pathogens including Porphyromonas gingivalis, Prevotella intermedia, Bacteroides forsythus and Actinobacillus aggregatibacter have been identified in significant quantities in atheromatous plaques, suggesting colonization of emigrated oral bacteria in systemic macrovasculature. ${ }^{82-85}$ Furthermore, the Oral infections and vascular disease epidemiology study (INVEST) has analyzed 657 dentate subjects with a mean age of 69 years having no history of stroke or $\mathrm{Ml}$ in order to investigate the relationship between oral microbiota and subclinical atherosclerosis, and found a positive correlation between the four bacterial species and carotid artery intima-media thickness (IMT). ${ }^{86}$ The INVEST group has recently reported a direct positive correlation between levels of subgingival bacteria and prevalence of hypertension. ${ }^{87}$ Nonetheless, the more frequent detection of $P$. gingivalis in type 2 diabetes patients with higher $\mathrm{HbA}_{1 \mathrm{c}}$ levels after periodontal therapy indicates that PD may have an impact on BG control in diabetes patients. ${ }^{88}$

\section{Conclusion}

PDs are more prevalent and severe in patients with diabetes. Compelling evidence demonstrates that diabetes is a major risk factor for periodontitis regardless of subgingival plaque. Several lines of evidence suggest a potential role of periodontitis in the onset of diabetes and glycemic control through inflammatory and infectious mechanisms. Treatment of periodontitis in diabetic patients results in a modest but significant reduction in $\mathrm{HbA}_{1 \mathrm{c}}$ levels and thus in better glycemic control. Larger clinical trials are needed to characterize the role of specific periodontal therapies in controling diabetes.
1. Centers for Disease Control and Prevention, National diabetes fact sheet: national estimates and general information on diabetes and prediabetes in the United States, 2011, Available at: www.cdc.gov/diabetes/pubs/pdf/ndfs_2011.pdf (accessed June 25, 2012).

2. Ranney R, Discussion: pathogenesis of gingivitis, I Clin Periodontol, 1985:13:356-9.

3. Lang NP, Schätzle MA, Löe $H$, Gingivitis as a risk factor in periodontal disease, J Clin Periodontol, 2009;36(Suppl. 10):3-8.

4. The effect of intensive treatment of diabetes on the development and progression of long-term complications in insulin-dependent diabetes mellitus. The Diabetes Control and Complications Trial Research Group, N Eng/ J Med, 1993:329:977-86.

5. Effect of intensive blood-glucose control with metformin on complications in overweight patients with type 2 diabetes (UKPDS 34). UK Prospective Diabetes Study (UKPDS) Group Lancet, 1998;352:854-65.

6. Tight blood pressure control and risk of macrovascular and microvascular complications in type 2 diabetes: UKPDS 38. UK Prospective Diabetes Study Group, BMI, 1998:317:703-13.

7. Löe $\mathrm{H}$, Periodontal disease. The sixth complication of diabetes mellitus, Diabetes Care, 1993;16:329-34.

8. Glavind, L, Lund B, Löe H, The relationship between periodontal state and diabetes duration, insulin dosage and retinal changes, J Periodontol, 1968;39:341-7.

9. Belting C, Hiniker J, Influence of diabetes mellitus on the severity of periodontal disease, J Periodontol, 1964;35:476-80.

10. Mealey BL, Ocampo GL, Diabetes mellitus and periodontal disease, Periodontol 2000, 2007:44:127-53.

11. Demmer RT, Desvarieux M, Holtfreter B, et al., Periodontal status and A1C change: Iongitudinal results from the study of health in Pomerania (SHIP), Diabetes Care, 2010;33:1037-43.

12. Soskolne WA, Klinger $\mathrm{A}$, The relationship between periodontal diseases and diabetes: an overview, Ann Periodontol, 2001;6:91-8

13. Taylor GW, Borgnakke WS, Periodontal disease: associations with diabetes, glycemic control and complications, Oral Dis, 2008;14:191-203.

14. Taylor GW, Bidirectional interrelationships between diabetes and periodontal diseases: an epidemiologic perspective, Ann Periodontol, 2001;6:99-112.

15. Lalla E, Cheng B, Lal $\mathrm{S}$, et al., Diabetes mellitus promotes periodontal destruction in children, I Clin Periodontol,
2007:34:294-8

16. Mattout C, Bourgeois D, Bouchard P, Type 2 diabetes and periodontal indicators: epidemiology in France 2002-2003, J Periodont Res, 2006;41:253-8.

17. Novak KF, Taylor GW, Dawson DR, et al., Periodontitis and gestational diabetes mellitus: exploring the link in NHANES III, J Public Health Dent, 2006;66:163-8.

18. Sarelius IH, Kuebel JM, Wang J, Huxley VH, Macromolecule permeability of in situ and excised rodent skeletal muscle arterioles and venules, Am J Physiol Heart Circ Physiol, 2006;290:H474-80.

19. Andriankaja OM, Barros SP, Moss K, et al., Levels of serum interleukin (IL)-6 and gingival crevicular fluid of IL-1beta and prostaglandin $\mathrm{E}(2)$ among non-smoking subjects with gingivitis and type 2 diabetes, J Periodontol, 2009;80:307-16.

20. Salvi GE, Franco LM, Braun TM, et al., Pro-inflammatory biomarkers during experimental gingivitis in patients with type 1 diabetes mellitus: a proof-of-concept study, I Clin Periodontol, 2010;37:9-16.

21. Tsai C, Hayes C, Taylor GW, Glycemic control of type 2 diabetes and severe periodontal disease in the US adult population, Community Dent Oral Epidemiol, 2002;30:182-92.

22. Firatli $E$, The relationship between clinical periodontal status and insulin-dependent diabetes mellitus. Results after 5 years, J Periodontol, 1997;68:136-40.

23. Oliver RC, Tervonen T, Periodontitis and tooth loss: comparing diabetics with the general population, I Am Dent Assoc, 1993;124:71-6.

24. Novaes AB Jr, Gutierrez FG, Novaes AB, Periodontal disease progression in type II non-insulin-dependent diabetes mellitus patients (NIDDM). Part I - Probing pocket depth and clinical attachment, Braz Dent J, 1996;7:65-73.

25. Seppälä B, Ainamo J, A site-by-site follow-up study on the effect of controlled versus poorly controlled insulin-dependent diabetes mellitus, J Clin Periodontol, 1994;21:161-5.

26. DePommereau V, Dargent-Paré C, Robert JJ, Brion M, Periodontal status in insulin-dependent diabetic adolescents, J Clin Periodontol, 1992:19:628-32.

27. Bridges RB, Anderson JW, Saxe SR, et al., Periodontal status of diabetic and non-diabetic men: effects of smoking, glycemic control, and socioeconomic factors, J Periodontol, 1996;67:1185-92
28. Sastrowijoto $\mathrm{SH}$, Hillemans $\mathrm{P}$, van Steenbergen $\mathrm{TJ}$, et al., Periodontal condition and microbiology of healthy and diseased periodontal pockets in type 1 diabetes mellitus patients, J Clin Periodontol, 1989;16:316-22.

29. Cutler CW, Machen RL, Jotwani R, lacopino AM, Heightened gingival inflammation and attachment loss in type 2 diabetics with hyperlipidemia, J Periodontol, 1999:70:1313-21.

30. Al-Zahrani MS, Bissada NF, Borawskit EA, Obesity and periodontal disease in young, middle-aged, and older adults, J Periodontol, 2003;74:610-5.

31. Genco RJ, Grossi SG, Ho A, Nishimura F, Murayama Y, A proposed model linking inflammation to obesity, diabetes, and periodontal infections, I Periodontol, 2005:76(11 Suppl .):2075-84.

32. Nibali L, D'Aiuto F, Griffiths G, et al., Severe periodontitis is associated with systemic inflammation and a dysmetabolic status: a case-control study, I Clin Periodontol, 2007;34:931-7.

33. Grossi SG, Zambon JJ, Ho AW, et al., Assessment of risk for periodontal disease. I. Risk indicators for attachment loss, J Periodontol, 1994;65:260-7.

34. Thorstensson $\mathrm{H}$, Kuylenstierna J, Hugoson A, Medical status and complications in relation to periodontal disease experience in insulin-dependent diabetics, I Clin Periodontol, 1996;23:194-202.

35. Saremi A, Nelson RG, Tulloch-Reid M, et al., Periodontal disease and mortality in type 2 diabetes, Diabetes Care, 2005;28:27-32.

36. Shultis WA, Weil EJ, Looker HC, et al., Effect of periodontitis on overt nephropathy and end-stage renal disease in type 2 diabetes, Diabetes Care, 2007;30:306-11.

37. Taylor GW, Burt BA, Becker MP, et al., Severe periodontitis and risk for poor glycemic control in patients with non-insulin-dependent diabetes mellitus, J Periodontol, 1996:67(10 Suppl):1085-93.

38. Ide R, Hoshuyama T, Wilson D, et al., Periodontal disease and incident diabetes: a seven-year study, J Dent Res, 2011;90:41-6.

39. Simpson TC, Needleman I, Wild SH, et al., Treatment of periodontal disease for glycaemic control in people with diabetes, Cochrane Database Syst Rev, 2010;CD004714.

40. Grossi SG, Skrepcinski FB, DeCaro T, et al., Treatment of periodontal disease in diabetics reduces glycated hemoglobin, J Periodontol, 1997;68:713-9.

41. Katagiri $S$, Nitta H, Nagasawa T, et al., Multi-center 
intervention study on glycohemoglobin (HDA1C) and serum, high-sensitivity CRP (hs-CRP) after local anti-infectious periodontal treatment in type 2 diabetic patients with periodontal disease, Diabetes Res Clin Pract, 2009;83:308-15.

42. Correa FO, Gonçalves D, Figueredo CM, et al., Effect of periodontal treatment on metabolic control, systemic inflammation and cytokines in patients with type 2 diabetes, J Clin Periodontol, 2010;37:53-8.

43. O'Connell PA, Taba M, Nomizo A, et al., Effects of periodontal therapy on glycemic control and inflammatory markers, I Periodontol, 2008;79:774-83.

44. Sun WL, Chen LL, Zhang SZ, et al., Changes of adiponectin and inflammatory cytokines after periodontal intervention in type 2 diabetes patients with periodontitis, Arch Oral Biol, 2010;55:970-4

45. Teeuw WJ, Gerdes VE, Loos BG, Effect of periodontal treatment on glycemic control of diabetic patients: a systematic review and meta-analysis, Diabetes Care, 2010:33:421-7.

46. Simpson T, Needleman I, Wild SH, Treatment of periodontal disease for glycaemic control in people with diabetes, Aust Dent J, 2010;55:472-4

47. Kiran M, Arpak N, Unsal E, Erdogan MF, The effect of improved periodontal health on metabolic control in type 2 diabetes mellitus, I Clin Periodontol, 2005:32:266-72.

48. Jones JA, Miller DR, Wehler $\mathrm{CJ}$, et al., Does periodontal care improve glycemic control? The Department of Veterans Affairs Dental Diabetes Study, I Clin Periodontol, 2007;34:46-52.

49. Rocha M, Nava LE, Vázquez de la Torre C, et al., Clinical and radiological improvement of periodontal disease in patients with type 2 diabetes mellitus treated with alendronate: a randomized placebo-controlled trial, J Periodontol, 2001;72:204-9.

50. Al-Mubarak S, Ciancio S, Aljada A, et al., Comparative evaluation of adjunctive oral irrigation in diabetics, I Clin Periodontol, 2002;29:295-300.

51. Rodrigues DC, Taba MJ, Novaes AB, et al., Effect of nonsurgical periodontal therapy on glycemic control in patients with type 2 diabetes mellitus, J Periodontol, 2003:74:1361-7.

52. Stewart JE, Wager KA, Friedlander $\mathrm{AH}$, Zadeh $\mathrm{HH}$, The effect of periodontal treatment on glycemic control in patients with type 2 diabetes mellitus, I Clin Periodontol, 2001;28:306-10.

53. Promsudthi A, Pimapansri S, Deerochanawong C, Kanchanavasita W, The effect of periodontal therapy on uncontrolled type 2 diabetes mellitus in older subjects, Oral Dis, 2005;11:293-8.

54. Darré L, Vergnes JN, Gourdy P, Sixou M, Efficacy of periodontal treatment on glycaemic control in diabetic patients: A meta-analysis of interventional studies, Diabetes Metab, 2008;34:497-506

55. Stratton IM, Adler Al, Neil HA, et al., Association of glycaemia with macrovascular and microvascular complications of type 2 diabetes (UKPDS 35): prospective observational study, BMJ, 2000;321:405-12.

56. Khaw KT, Wareham N, Bingham S, et al., Association of hemoglobin A1c with cardiovascular disease and mortality in adults: the European prospective investigation into cancer in Norfolk, Ann Intern Med, 2004;141:413-20.

57. Mealey BL, Rose LF, Diabetes mellitus and inflammatory periodontal diseases, Curr Opin Endocrinol Diabetes Obes, 2008;15:135-41.

58. Mealey BL, Oates TW, American Academy of Periodontology, Diabetes mellitus and periodontal diseases, J Periodontol, 2006;77:1289-303.

59. Manouchehr-Pour M, Spagnuolo PJ, Rodman HM, Bissada NF, Impaired neutrophil chemotaxis in diabetic patients with severe periodontitis, I Dent Res, 1981;60:729-30

60. McMullen JA, Van Dyke TE, Horoszewicz HU, Genco RJ, Neutrophil chemotaxis in individuals with advanced periodontal disease and a genetic predisposition to diabetes mellitus, J Periodontol, 1981;52:167-73.

61. Graves DT, Liu R, Alikhani M, et al., Diabetes-enhanced inflammation and apoptosis - impact on periodonta pathology, J Dent Res, 2006:85:15-21.

62. Salvi GE, Collins JG, Yalda B, et al., Monocytic TNF alpha secretion patterns in IDDM patients with periodontal diseases, J Clin Periodontol, 1997;24:8-16

63. Lalla E, Kaplan S, Yang J, et al., Effects of periodontal therapy on serum C-reactive protein, $\mathrm{SE}$-selectin, and tumor necrosis factor-alpha secretion by peripheral blood-derived macrophages in diabetes. A pilot study, J Periodontal Res, 2007;42:274-82

64. Sima C, Rhourida K, Van Dyke TE, Gyurko R, Type 1 diabetes predisposes to enhanced gingival leukocyte margination and macromolecule extravasation in vivo, I Periodontal Res, 2010;45:748-56.

65. Gyurko R, Siquiera CC, Caldon N, et al., Chronic hyperglycemia predisposes to exaggerated inflammatory response and leukocyte dysfunction in Akita mice, I Immunol, 2006;177:7250-6.

66. He H, Liu R, Desta T, et al., Diabetes causes decreased osteoclastogenesis, reduced bone formation, and enhanced apoptosis of osteoblastic cells in bacteria stimulated bone loss, Endocrinology, 2004:145:447-52.

67. Liu R, Bal HS, Desta T, et al., Tumor necrosis factor-alpha mediates diabetes-enhanced apoptosis of matrix-producing cells and impairs diabetic healing, Am J Pathol, 2006;168:757-64.

68. White CB, Turner NS, Lee G-C, Haidukewych GJ, Open ankle fractures in patients with diabetes mellitus, Clin orthop Relat Res, 2003:414:37-44.

69. Beam HA, Parsons JR, Lin SS, The effects of blood glucose control upon fracture healing in the BB Wistar rat with diabetes mellitus, J Orthop Res, 2002;20:1210-16.

70. Tonetti MS, D'Aiuto F, Nibali L, et al., Treatment of periodontitis and endothelial function, $N$ Eng/ I Med, 2007;356:911-20

71. Engebretson S, Chertog R, Nichols A, et al., Plasma levels of tumour necrosis factor-alpha in patients with chronic periodontitis and type 2 diabetes, I Clin Periodontol, 2007;34:18-24.
72. Lalla E, Lamster IB, Feit M, et al., Blockade of RAGE suppresses periodontitis-associated bone loss in diabetic mice, I Clin Invest, 2000;105:1117-24.

73. Takeda M, Ojima M, Yoshioka H, et al., Relationship of serum advanced glycation end products with deterioration of periodontitis in type 2 diabetes patients, I Periodontol 2006;77:15-20

74. Murillo J, Wang $Y, X u X$, et al., Advanced glycation of type I collagen and fibronectin modifies periodontal cell behavior J Periodontol, 2008;79:2190-9.

75. Davé S, Van Dyke T, The link between periodontal disease and cardiovascular disease is probably inflammation, Oral Dis, 2008:14:95-101.

76. Beck J, Garcia R, Heiss G, et al., Periodontal disease and cardiovascular disease, J Periodontol, 1996;67(10 Suppl.):1123-37.

77. Friedewald VE, Kornman KS, Beck JD, et al., The American Journal of Cardiology and Journal of Periodontology editors consensus: periodontitis and atherosclerotic cardiovascular disease, J Periodontol, 2009;80:1021-32.

78. Loos BG, Systemic markers of inflammation in periodontitis, J Periodontol, 2005;76(11 Suppl.):2106-15

79. Noack B, Genco RJ, Trevisan M, et al., Periodontal infections contribute to elevated systemic C-reactive protein level, J Periodontol, 2001:72:1221-7.

80. Okabe K, Nakagawa K, Yamamoto E, Factors affecting the occurrence of bacteremia associated with tooth extraction, Int I Oral Maxillofac Surg, 1995;24:239-42.

81. Yoshii S, Tsuboi S, Morita I, et al., Temporal association of elevated C-reactive protein and periodontal disease in men, J Periodontol, 2009:80:734-9.

82. Nakano $\mathrm{K}$, Nemoto $\mathrm{H}$, Nomura $\mathrm{R}$, et al., Detection of oral bacteria in cardiovascular specimens, Oral Microbiol Immunol, 2009;24:64-8.

83. Koren O, Spor A, Felin J, et al., Human oral, gut, and plaque microbiota in patients with atherosclerosis, Proc Natl Acad Sci U S A, 2011:108(Suppl. 1):4592-8.

84. Haraszthy VI, Zambon JJ, Trevisan M, et al., Identification of periodontal pathogens in atheromatous plaques, I Periodonto 2000;71:1554-60

85. Toyofuku T, Inoue $\mathrm{Y}$, Kurihara N, et al., Differential detection rate of periodontopathic bacteria in atherosclerosis, Surg Today 2011;41:1395-400.

86. Desvarieux M, Demmer RT, Rundek T, et al., Periodontal microbiota and carotid intima-media thickness: the Oral Infections and Vascular Disease Epidemiology Study (INVEST), Circulation, 2005;111:576-82

87. Desvarieux M, Demmer RT, Jacobs DR Jr, et al., Periodontal bacteria and hypertension: the oral infections and vascular disease epidemiology study (INVEST), J Hypertens, 2010;28:1413-21.

88. Makiura N, Ojima M, Kou Y, et al., Relationship of Porphyromonas gingivalis with glycemic level in patients with type 2 diabetes following periodontal treatment, Oral Microbiol Immunol, 2008;23:348-51. 